\title{
دور اللوبي الصـهيوني في صنع السياسة الأمريكية
}

\author{
المدرس الدكثور اسعد \\ أ . م. . د. . داود مر اد حسين(*) \\ غاللي حمزة)(**)
}

\section{المبحث الاول : ماهية القوى المؤثرة في النظم السياسية}

لا تتحدد معالم المؤسسات الدستورية في الدول ذات الصبغة الديمقراطية التي

توضح طبيعة اهدافها الا من خلال تأثير القوى السياسية والاجتماعية ، وتملك هذه القوى تأثيراً كبيراً في تكوين هذه المؤسسات الدستورية ولاسيما السلطتين التنفيذية والتشريعية وذلك عن طريق الانتخابات ، كما تؤثر في سير وانتظام هاتين المؤسستين من خلال الموالاة او المعارضة لسياستها ، وتستخدم في ذلك عدة وسائل دستورية وعملية .

ومارست جماعات الضغط تأثيراً لا يستهان به في الحياة السياسية قد يوازي

الدور الذي تلعبه الاحزاب السياسية لذلك يتوجب علينا تحديد المقصود بجماعات الضغط وطبيعة علاقتها بالاحزاب السياسية والوسائل التي تنتهجها للتأثير في السلطات داخل الدول، واخيراً يتوجب علينا التطرق الى اهم انواع جماعات الضغط الاوهي اللوبي

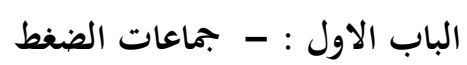

من الصعوبة بمكان اعطاء تعريف جامع ومانع لجماعات الضغط ، ولكن بالامكان الاستدلال على مجموعة من العناصر الاساسية التي تعطي وصفاً دقيقاً لها ، فهي عدد كبير من الجماعات والجمعيات والنقابات والشركات تلجأ الى مجموعة من الوسائل والاليات المختلفة لتحقيق مصالح اعضائها او القيم التي يؤمنون بها وذلك بالتأثير على العمل الحكومي والبرلماني ، دون اغفال الرأي العام وتوجيهه بالصورة التي تضمن مصالح وقيم الجماعات . ونستنتج من هذه العناصر الاساسية والمتمثلة بحد ادلى من التنظيم والبنيوية للتجمع، بجموعة من الافراد يسهمون في حياة التجمع، ويتميزون بمواقف شخصية وبماعية تسهل عملية التضامن فيما بينهم، ويعملون على صعيد المجتمع ككل او على الصعيد المحلي، ويدافعون عن مصالح أعضائهم المشتركة(1). 
وتتنوع جماعات الضغط من حيث ابتاهاتا وتركيبتها ، فهناك التجمعات الايديولوجية أو الاخلاقية او الفكرية او الدينية والنقابات المختلفة ، وتتنوع جماعات الضغط من حيث محور عملها ، فهناك جماعات تركز على التأثير على السلطة وأخرى لا تمارس الضغط على السلطة الا بصورة تبعية ، إذ تمارس الى جانب ذلك نشاطات أخرى صناعية وانتاجية وبتارية تسمى جماعات ضغط بالتبعية ( Accessory ) ويمكن تقسيم مفهوم جماعات الضغط الى شقين الاول يتمحور حول الجماعة والاخر حول مفهوم الضغط . ويقصد بالجماعة ( Group ) أي ائتلاف بين بجموعة من الاشخاص لم خصائص عامة مشتركة مثل ، مستوى معين من المعيشة والدخل ، اصحاب مهنة واحدة ، تشابه في السلوك العام ، مستوى ثقافي وعلمي متقارب ، حالة اجتماعية متقاربة ، ومصالح واهداف متقاربة ، ينتمون الى جنس ومذهب ديني واحد . اما المفهوم الاخر الضغط ( Pressure ) فانه مرتبط بالعملية السياسية ، اذ يعني ان الجماعة سالفة الذكر قد انتهجت رأياً موحداً فيما يخص موضوع معين من اجل وضع الرأي موضع التنفيذ في الواقع السياسي ، وبالتالي نلاحظ ان جماعات الضغط تحاول التأثير في صانعي القرارات في النظام السياسي من اجل تحقيق غرضهم على وفق مصالحهم ( 2 ) . وأيا ما كانت التسمية ، فقد تعددت جماعات الضغط في مختلف بقاع العالم ولاسيما عقب الثورة الصناعية وما تلاها من ثورة تكنلوجية ، واخيراً الثورة المعلوماتية وانظمة التواصل الاجتماعي ، حتى بلغ عدد جماعات الضغط في الولايات المتحدة وحدها ما يزيد على 2500 جماعة ضغط ـ ولم يقتصر دور هذه الجماعات على الكونغرس الامريكي بل تحاول هذه الجماعات الاتصال بدوائر الاجهزة التنفيذية في البيت الابيض والتأثير فيها لما تحمله هذه الاجهزة البيروقراطية من اهمية تكمن في كيفية تفسير قرارات الكونغرس الامريكي الامر الذي يجعلها هدفاً لجماعات الضغط ـ ففي حال صدور تشريع من الكونغرس يعارض او يتقاطع مع مصالح جماعات الضغط يحاول مندوبوها الذين يلقبون بـ(( Lobbyists ())، والتي يرمز بها الى الممرات وغرف الانتظار والمداخل حيث يتردد فيها أشخاص كثيرون على لم المجالس التشريعية في محاولة للتأثير في اعضائها لمصلحتهم ، وفي مسعاهم هذا ينشدون رجال الحكومة ومن يمثلهم في المجالس النيابية ليستجيبوا لمطالبهم ومصالحهم الخاصة عن طريق 
القوانين التي تغدق عليهم الكثير من الحقوق . وهذه الممرات والدهاليز هي بمثابة المأوى لحقوق جماعات الضغط وهي تشبه المنابر التي تصدح بالكلمات التي تؤيد حقوقهم ضمن الاطار العام للنظام ، ومنها يتوجهون لتفسير مطالبيهم والدفاع عن حقوقهم ( 3 ). وتحاول جماعات الضغط وضع العراقيل والعوائق على مشاريع القوانين التي تضر بمصالحهم وذلك عن طريق التأثير في الجهات التنفيذية بحيث يتم تفسير مشاريع القوانين بشكل يخفف من الاضرار التي قد تلحق بهم ، وعلى الرغم من الانتقادات التي يتم توجيهـا الم هذه الجماعات فهناك من يدافع عنها ، كوها تشكل دعامة وركيزة اساسية للخدمات وهي خزينة للمعلومات التي يلجأ اليها صانعوا السياسة والقرارات الحلكومية ، فأعضاء البرلمان والحكومة بحاجة دائمة ومستمرة لهذه الجماعت للحصول على الارشادات والمعلومات حتى يتسنى لهم وضع القواعد الاساسية فيما يخص تشريع القوانين ( 4 ). وتعتبر جماعات الضغط بمختلف صنوفها احد اهم الدعائم الاساسية للدول ذات الصبغة الديمقراطية الحديثة وكبر دليل على ذلك ما اشترطه المفكر السياسي ( روبرت داهل ) وجود عشرين نوعاً من انواع المؤسسات السياسية المختلفة في النظام السياسي لكي يعطيه الصفة الديمقراطية واول هذه المؤسسات هي (( الحرية لتشكيل المنظمات وحرية الانضمام لعضويتها )) ، واكد أيضاً (( ان جماعات الضغط والمصالح هي وسائل فعالة لمساعدة الاقليات في الافصاح عن رغبتها والتأثير على قرارات الحكومة لتحقيق مصالحها )) ( 5 ). X

قبل الخوض في طبيعة العلاقة بين جماعات الضغط والاحزاب السياسية يتوجب علينا التعرف على ماهية الاحزاب السياسية ، وفي الحقيقة ان وجود الاحزاب السياسية بصورتا القديمة سابقة لوجود السياسة ، ولكن لم تكن هذه الاحزاب سوى تجمعات غير منظمة ، بل كانت عبارة عن بجمعات عفوية لبعض الشخصيات مدفوعة ببعض المثل العليا هدفها البحث والمداولة في مشكالات الساعة المطروحة في الدولة دون محاولة فرض وجهة نظرها من خلال ايجاد الحل الذي تراه مناسباً لمذه المشكلة ، وانتقل المفهوم السابق وبشكل متلاحق ليصبح اهم نتائج وضرورات النظام الديمقراطي التمثيلي في وقتنا الحالي ( 6 ) ، فعلى الرغم من ان رجال الثورة الفرنسية كانوا يرون ان هناك تعارضاً بين الصفة التمثيلية لعضو 
البرلمان وبين وجود الاحزاب ، فقد ولدت الاحزاب نتيجة للنظام التمثيلي وفي قلب البرلمان وبشكل عفوي ، فقد كان البرلمانيون ممن يحملون اتجاهات سياسية متقاربة يجلسون في البرلمان وبشكل عفوي على مقاعد متقاربة ، ويجرون فيما بينهم اجتماعات خاصة من اجل توحيد مواقفه حول المسائل المطروحة أمامهم ، ومن هنا نشأ ما يسمى بالتجمعات أو الكتل البرلمانية والتي لم يكن لها سابق وجود على الصعيد الرسمي ( 7 ) . ولكن هذه الأحزاب لم تكن بداية سوى أحزاب نخبة وليست أحزاباً جماهيرية فالسياسيون كانوا بأغلبيتهم من النبلاء أو من الطبقة الوسطى الطموحة التي لم كتم للمسائل الاجتماعية وخاصة قضايا العمال التي كانت مجهولة من قبلهم وكرد فعل ضد ما عدّ مصادرة للاقتراع العام من قبل البرجوازية الصغيرة تشكلت الأحزاب الجماهيرية التي أحدثت تحولا مهماً في تاريخ المؤسسات السياسية . ويمكن تعريف الحزب السياسي بأنه مجموعة من الإفراد لمم تنظيم دائم على المستوى الوطني ، تسعى للوصول إلى السلطة وممارستها بالطرق المشروعة ، من اجل تنفيذ سياسة محددة ( 8 ) . ومن خلال هذا التعريف نستطيع التعرف على خصائص الأحزاب ومقارنتها بجماعات الضغط لاستخلاص نقاط التقارب ونقاط الاختلاف ، ويمكن إجمالي خصائص

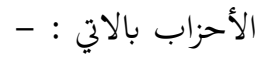

1. الديمومة : - تمتاز الأحزاب بصفة الديمومة والاستمرار أي انه ليس مرحلي ولد من

اجل معالجة مشكلات وجدت في حقبة زمنية محددة والانحلال من بعد ذلك . 2. تنظيمها على مستوى وطني : - على الحزب أن يمتلك تنظيماً متكاملاً على المستوى الوطني وله فروع في جميع أو معظم أقاليم الدولة أما إذا كان هذا التجمع

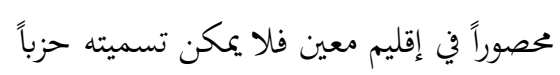
3. هدف الوصول إلى السلطة : - يعدّ الهدف الأساسي للحزب السياسي العمل للوصول إلى الحكم وان تكون له إرادة معلنة هدفها الوصول إلى مقاليد السلطة سواء بمفرده أو بالتحالف مع قوى وأحزاب أخرى ، أما إذا كان هدفه فقط التأثير في الحياة السياسية والتأثير على السلطة فيصنف هذا التجمع على انه قوة ضغط ، وان يسلك الطرق الدستورية والقانونية للوصول إلى السلطة حتى لا يتحول إلى تنظيم أو مجموعة مسلحة والتي تحف للوصول إلى الحكم بطرق غير مشروعة . 
ونستخلص من هذا التعريف والخصائص سابقة الذكر جوهر وطبيعة الخلاف حيث

تختلف الأحزاب السياسية عن جماعات الضغط بشكل جوهري في شقين الأول خاص بالأهداف والأخر الإغراض لكل منهما لان الحزب يهدف من عمله السياسي الوصول للحكم والسلطة في حين ان غرض جماعات الضغط يقتصر فقط على التأثير على السلطة

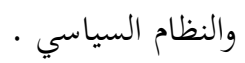

وهذا لا يعني عدم وجود أية روابط بين جماعات الضغط والاحزاب السياسية ، فقد

يكون هناك بعض الاشخاص أعضاء في حزب ما ونقابة معينة في أن واحد ، وقد يكون مجرد الانتساب الى نقابة ما يؤدي تلقائياً الى الانضمام الى حزب بذاته كما هو الحال فيما يتعلق بجزب العمال البريطاني الذي يضم في طياته اعضاء وافراد عاديين وجماعات تمثل النقابات العمالية والتي كانت وراء نشأة الحزب وظهور الى النور في العام 1900 ، وقد تسهم جماعات الضغط في وصول احد الاحزاب للسلطة من خلال مناصرته ، ففي الجمهورية الفرنسية مثلاً توجد عدة نقابات عمالية كل منها تناصر احدى الجهات الحزبية ، حيث نقابة (الحية ( C.F.D.T ونقابة ( F.O ) - F.O ) - موى العمال - والتي تناصر الاشتراكية الدولية ، وفي الولايات المتحدة الامريكية تناصر الفدرالية الامريكية للعمل ( A.F.L ) مرشحي الحزب الديمقراطي بأستمرار ( 9 ( ) مريكه

\section{وسائل تأثير جماعات الضغط .}

\section{X}

تختلف الطرق والوسائل التي تنتهجها جماعات الضغط والتي تلجأ اليها للتأثير على عمل السلطة بأختلاف طبيعة اواهداف كل جماعة ، وتختلف بأختلاف الظروف التاريخية والموضوعية في كل دولة ويمكن حصر وتقسيم هذه الوسائل الى ثلاث فئات ( 10 ) . الفئة الأولى : - الاتصال أو الاحتكاك غير المباشر مع السلطة أو النظام السياسي من خلال تسخير وسائل الإعلام ، أو من خلال التهديد أو اللجوء إلى عمليات الاحتجاج أو الإضراب الأمر الذي يقود في بعض الحالات إلى اتصال مباشر مع السلطة من خلال التفاوض مع المضربين أو المحتجين . 
ل الفئة الثانية : - الاتصال أو الاحتكاك المباشر مع اصحاب القرار في السلطة (ألة وزراء ، نواب ، اداريون كبار ، شخيات مؤثرة كأعضاء احزاب الاغلبية ) ويتم ذلك من خلال استغلال العلاقات الشخصية ، او من خلال اقامة الحفلات وتنظيمها ، او عقد الاجتماعات ، أو اللقاءات التي تعد لمناقشة المسائل والمواضيع المطروحة على الساحة السياسية ، او من خلال المشاورات او المفاوضات الرسمية وغير الرسمية بين السلطة وممثلي هذه الجماعات ، ففي فرنسا مثلا ونتيجة للدور الذي تلعبه جماعات الضغط ظهر مؤخراً ما يسمى بسياسة التشاور أو الاستئناس ( Public

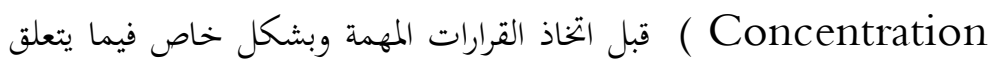
بالامور التي تمس شرائح كبيرة من المجتمع كقضايا العمل ، التعليم ، والصحة ...

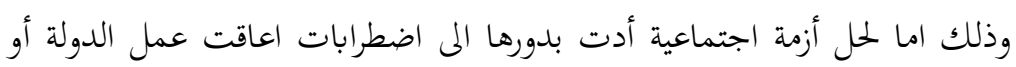

$$
\text { لتجنب حدوث ذلك . }
$$

ل الفئة الثالثة : - تتمثل في امكانية التأثير على السلطة من خلال أسهام جماعات

الضغط بصورة مباشرة أو غير مباشرة في الحملات الانتخابية للمرشحين ( 11 ) .

\section{الباب الثاني : - أللوبي ( Lobby Group ) .}

يمكن عدّ هذه القوى او الجماعة أحد اهم وابرز جماعات الضغط التي تمتاز بأسلوب خاص تحدف من خلاله التأثير بشكل مباشر في صانعي القرارات التشريعية ( 12). يقصد بتعبير اللوبي ( Lobby ) لغوياً الممر أو الدهليز ، وكانت ترمي أساساً للدلالة على دهاليز مجلس العموم البريطاني ، وظهر هذا المصطلح منذ القرن السابع عشر إذ كان البرلمانيون يصطدمون في اروقة بجلس العموم بالذين يحاولون التأثير على اصواتم، ومن ثم دخل هذا المفهوم الى باحة الولايات المتحدة الأمريكية في بداية القرن التاسع عشر. واللوبي هو فرد أو تنظيم يعمل لحساب الغير بهدف التأثير على قرارات السلطة، ومن هذا التعريف نستطيع أن نستخلص سماته واختلافه عن بقية جماعات الضغط الأخرى، فاللوبي ليس جماعة أو مجموعة بالضرورة، فيمكن أن يكون فرداً، واللوبي يعمل لمصلحة الغير، فرداً أو جماعة، وبالتالي فان الضغط الذي يمارسه فرد لمصلحته أو جماعة لمصلحتها لا يعدّ نوعاً من أنواع ضغط اللوبي ، واللوبي لاستهدف سوى التأثير على قرارات السلطة العامة في 
جميع مراحلها وفي جميع مستويات مؤسساتا ( سلطة تنفيذية ، برلمان ، محاكم ، منظمات

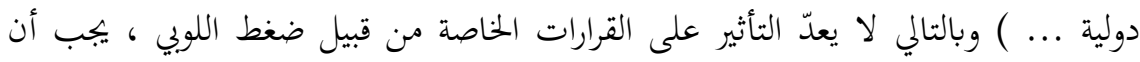

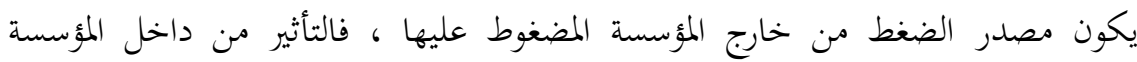

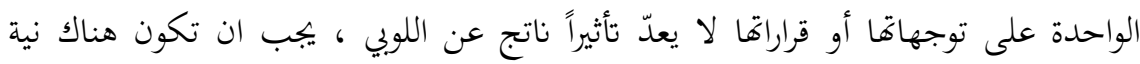

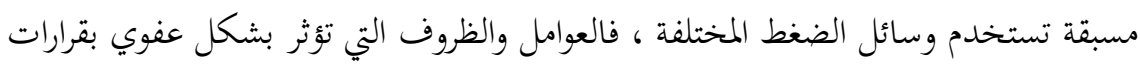

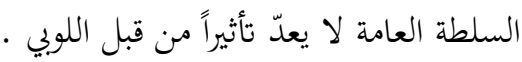
وفي الحالة الخاصة بالولايات المتحدة الأمريكية نجد أن تأثير اللوبي عمل على إفساد بلداد

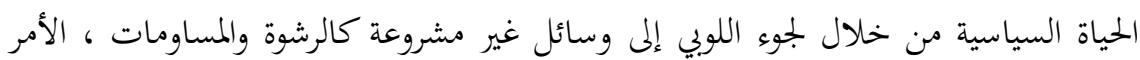

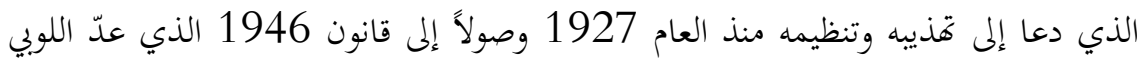

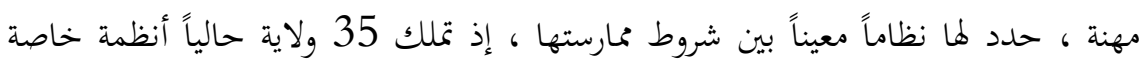

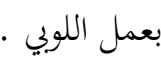

ونشأة هذه الظاهرة الفريدة من نوعها في الولايات المتحدة من قبل أصحاب المال والقوى الاقتصادية والسياسية ، وأخذت مسميات متعددة ارتبطت عادة بالجنسية الأصلية أو الو

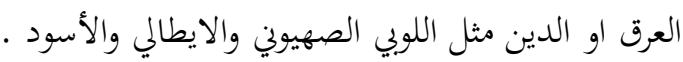
واصبحت ظاهرة اللوبيات صناعة بحد ذاتما وهي في تعاظم مطرد وبشكل خاص ولرد خلال السنوات 1970 - 1980 بسبب النصوص القانونية والدستورية التي وضعت لتنظيم

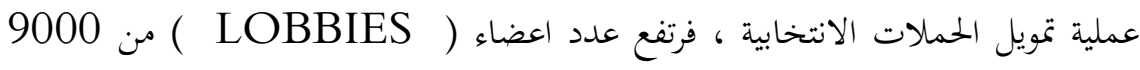

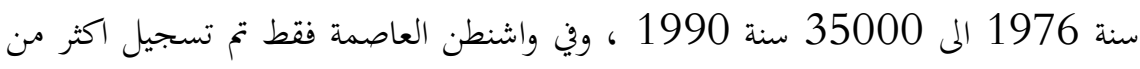

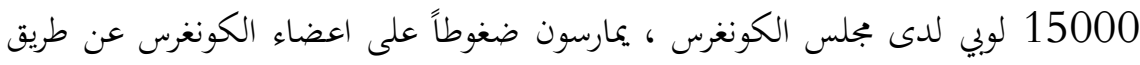

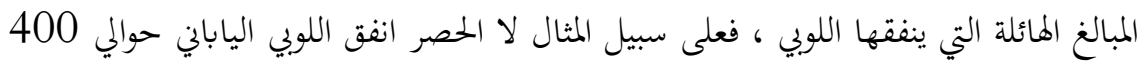

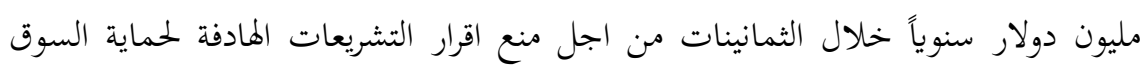

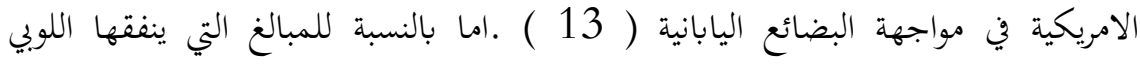

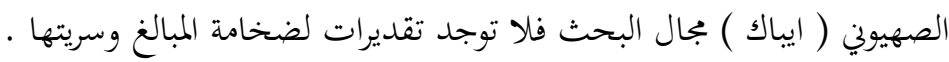

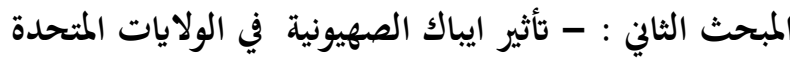
الباب الاول : - ايباك الاهداف واستراتيجية العمل . ل 
وهي لجنة الشوؤن العامة الأمريكية الإسرائيلية تم تأسيسها في العام 1951 من قبل أيزيا ل.سي.كينين* وي منتصف السبعينيات أستطاعت منظمة أيباك في تحقيق النفوذ المالي والسياسي اللازم للتأثير على اهم مفاصل النظام السياسي الامريكي الا وهو الكونغرس الأمريكي الامر الذي مكنها من مواجهة المعارضيين من مجلسي النواب والشيوخ (14) ، وتثبيت مكانتها كقوة رئيسية في صياغة السياسة الأمريكية بحاه الشرق الأوسط بشكل خاص والعالم بشكل عام (15)، وفي عام 1997 جاءت منظمة أيباك الثانية بعد الجمعية الأمريكية للناس المتقاعدين وقبل جماعات ضغط يتم تصنيفها من الوزن الثقيل في الولايات المتحدة مثل اتحاد العمل الأمريكي، مؤتمر المنظمات الصناعية، والجمعية الوطنية للبنادق طبقاً لمجلة فورتشين(16) ، كما جاءت أيضاً في المرتبة الثانية في دراسة أجرها مجلة ناشينول جورنال في مارس 2005 كأحد أقوى جماعات الضغط في عمليات فرز القوة في واشنطن (17) . وتتكون ايباك من يهود أمريكيين يبذلون جهدا كبيرا في حياهم اليومية من أجل

تسخير السياسة الخارجية الأمريكية لدعم مصالح الكيان الصهيوني وتتجاوز نشاطاتم مجرد التصويت لمرشحين موالين للكيان الصهيوني فتتضمن في أغلب الأحيان إسهامات مالية لتمويل حملات مرشحين بعينهم ، ودعم المنظمات الموالية لإسرائيل ، ولا يمكن عدّ كل يهودي أمريكي جزءا من اللوبي ، لأن الكيان الصهيوني ليست قضية بارزة للعديد منهم .ففي مسح أجري سنة ع . . ب على سبيل المثال ، قال نحو بr \% من الأمريكيين اليهود إفم غير مرتبطين عاطفياً بإسرائيل(18). وبرغم تغاير المواقف الأ أن معظم الأمريكيين اليهود متفقين على الدعم السياسي الأمريكي لإسرائيل ، أما على صعيد منظمة الأيباك فمن المتعارف عليه أها تدار من قبل متشددين يدعمون في العادة السياسات التوسعية لحزب الليكود الإسرائيلي، بما في ذلك العداء ضد عملية السلام وبالتحديد ما تمخضت عنه اتفاقية أوسلو للسلام(19)، وتضم أيباك في صفوفها بجموعة من البروتستانت الذين يعتقدون أن مولد الكيان الصهيوني من جديد جزء من نبوءة توارتية ويعتقدون أن الضغط على إسرائيل أمر

" إيزيا. ل. ل.سي . كينين عمل سابقاً كموظف في وزارة الحارجية الأسرائيلية وأدار اللجنة الصهيونية الأمريكية للشوؤن العامة

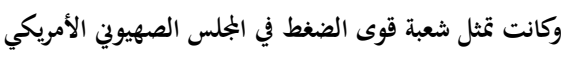


مخالف لإرادة الله (20)، ورسميا تصف أيباك نفسها كمنظمة تضم أعضاء مستقلين وأعضاء من الحزبين الجمهوري والديمقراطي (21) ، الأمر الذي يوفر لها الضغط المطلوب في الكونجرس الأمريكي (22) أنجين

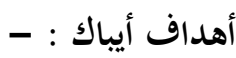

يذكر الموقع الرسمي للمنظمة بأن الهدف الرئيسي للمنظمة هو تقوية الروابط بين الولايات المتحـدة وحليفتها إسـرائيل عـن طريق أعضـاء المنظمـة مـن المستقلين والـيمقراطيين والجمهوريين الذي يحرصون على صياغة سياسـات عامـة قائمة على تعزيز العلاقـة الأمريكية الإسـرائيلية وحـث مـوظفي المنظمـة والناشـطين فيها لتثقيـف أصـحاب القـرار في الـولايات المتحدة الأمريكية حول تلك الروابط وأن من صالح الولايات المتحدة الأمريكية ضمان سلامة وأمن و قوة إسرائيل ، من خلال حث الكونجرس الأمريكي لتقديم المعونات بمختلف صورها إلى الجانب الإسرائيلي وإقامة شراكة من نوع خاص لمحاربة الإرهاب والترويج لدولة إسرائيلية إلى جانبها دولة فلسطينية غير المسلحة (23) ، ونجحت في تحقيق هـفها باستمالة سياسة الولايات المتحدة الخارجية وحرفها إلى ابتاهـات تحابيها وترضيها، ويرى الكاتبان جون .جي ميرشـايمر و سـتيفن.ام.والت" في بحثهمـا ( اللـوبي الإسـرائيلي والسياسـة الخارجيـة للـولايات المتحدة الأمريكية ) أن مواقف الولايات المتحدة من إسرائيل أدت إلى إلهاب مشاعر السخط في أوساط الرأي العام العربي والإسلامي ، وهددت أمن الولايات المتحدة الأمريكية ، وليس إله لهذه الحالة نظير في التاريخ السياسي الأمريكي حيث نحت الولايات المتحدة الأمريكية أمنها الخاص خدمة لمصالح دولة آخري (24) .

" دكتوري العلوم السياسية في جامعة هارفرد وتعرضت دراستهما التي صدرت في اذار 2006 في الولايات المتحدة الأمريكية

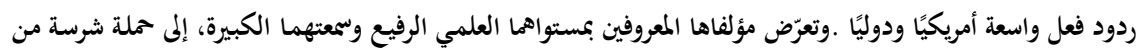

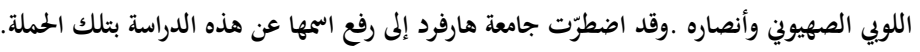


تستهدف منظمة أيباك الناشطين المؤيدين لإسرائيل بصرف النظر عن سنهم ،

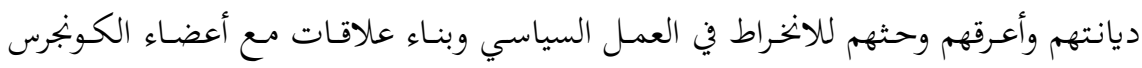

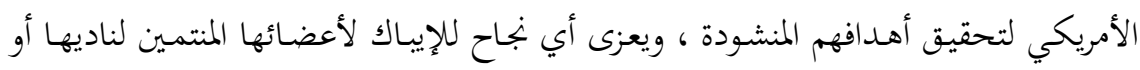
الذين يقدمون الدعم المالي لحملة الغد التابعة للمنظمة ، وحسب الموقع التابع للمنظمة تضم الأيباك أكثر من مئة ألف عضو عبر الولايات المتحدة الأمريكية . وعشرة مكاتب إقليمية في الولايات المتحـدة وأهمهم مكتـب الأيباك في العاصمة واشنطن . ويركز أيضاً أعضاء الأيباك على التواصل مع الكنائس والمئات مـن الجامعات والمدارس الثانوية لتعليمهم كيفية التصدي لمن يتصدي لإسـرائيل وسياستها وكيفيـة استخدام العمل السياسي ليصـب في صالح الدعم الأمريكي لإسرائيل (25) من لإسنريل استعطاف الأمريكيين سياسياً وشعبياً : - الإسرائ

1. يستغل الأيباك تاريخ المعاناة اليهودية في الغرب المسيحي ، وبخاصة أحداث المحرقة اليهودية واضطهاد اليهود على مدى القرون كحجة لوجود دولة إسرائيل ، واستحقاق الشعب اليهودي معاملة خاصة من قبل الولايات المتحدة ، ألا أن خلق الكيان الصهيوني تضمن جرائم إضافية ارتكبت ضد طرف أخر بريء إلا وهو الشعب الفلسطيني فعندما بدأت الصهيونية بخطواتما السياسية في أواخر القرن التاسع عشر، كان هنالك نخو 1 ألف يهودي فقط في فلسطين وفي عام ب9 1 1 1 على سبيل المثال ، كان العرب يشكلون نحو 90 \%من السكان وتحت سيطرة الدولة العثمانية (26) ، وعند تأسيس الكيان الصهيوني ، لم يشكل اليهود سوى هب \% فقط من سكان فلسطين ، ولم

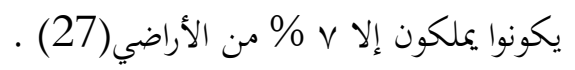

2. يسعى أعضاء الأيباك استعطاف الجمهور الأمريكي بوصف الدولة اليهودية على أها محاصرة من قبل أعدائها إذ افاد القادة الصهاينة والكتاب المتعاطفون مع إسرائيل لترسيخ هذه الصورة وتغذيتها وترويجها ، ولكن الواقع هو مخالف

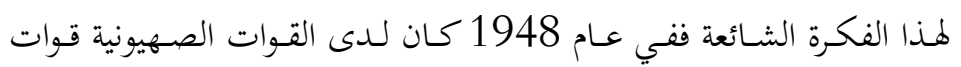
مسلحة أكبر عدداً ، وأفضل عتاداً وقيادة حققت من خلالها انتصارات ضد 
الجمهورية العربية المصرية عام 1956 وضد كل من مصر والأردن وسوريا عام 1967 (28) وذلك قبل تدفق المساعدات العسكرية المقدمة من الولايات

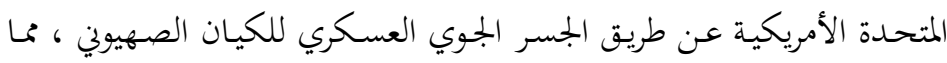

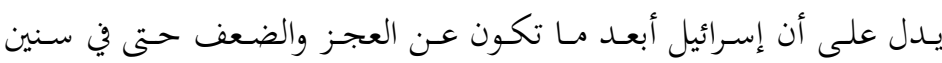

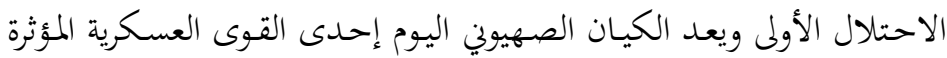
في الشرق الأوسط وهي الدولة الوحيدة التي تمتلك الأسلحة النووية وحسبما

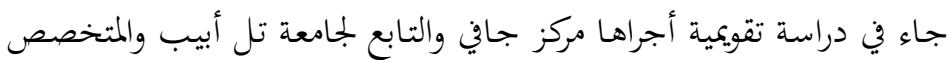

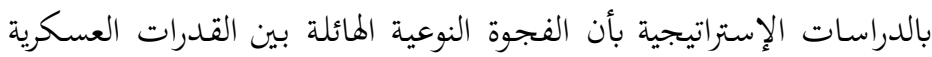
العربية وبين القدرات الإسرائيلية آخذة بالاتساع ، وقوة الردع الإسرائيلية في تعاظم مستمر، وهناك تفوق كاسح على جيراها (29) فإذا كانت نصرة الضعيف المظلوم والمضطهد تشكل أساسا منطقيا قاهرا تقتضيه منظومة المبادئ الخلقية، فعندها يجب على الولايات المتحدة أن تدعم خصوم الكيان الصهيوني وتب لنصرقم لاسيما بعد دراسة المنهجية العنيفة التي يتبعها الكيان

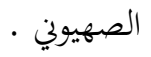

3. وصف الكيان الصهيوني بالدولة الديمقراطية والزميلة المحاطة بالدكتاتوريات

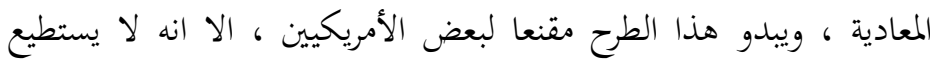

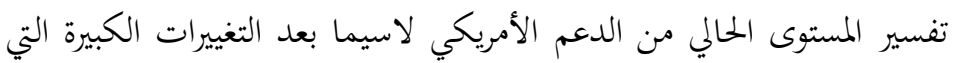
شهدةا المنطقة ، ولكن أياً منها لا يتلقى الدعم السخي الذي تتلقاه إسرائيل

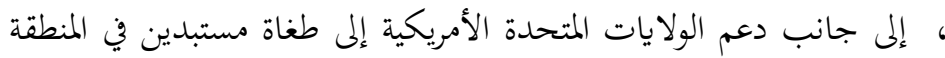

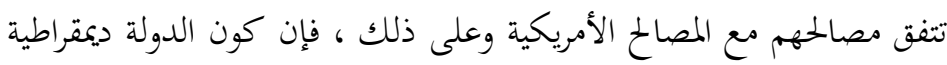

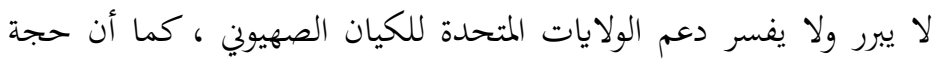

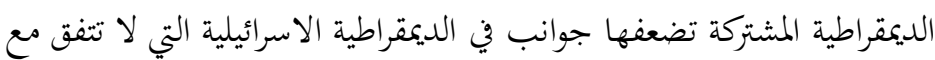
جوهر القيم الأمريكية ـ فالولايات المتحدة ترفع شعار النظام الديمقراطي

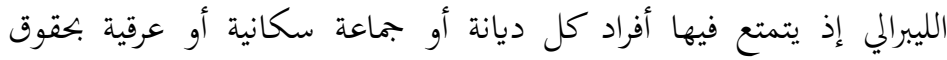

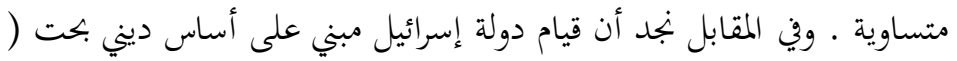


الديانة اليهودية ) ، كما أن حق المواطنة فيها مبني على قرابة الدم (30) ومع أخذ هذا المفهوم لحق المواطنة بعين الاعتبار، لا يبدو غريباً أن تجري معاملة عرب إسرائيل البالغ عددهم r، إ مليون نسمة مواطنين من الدرجة الثانية (31) وبالمثل لايسمح الكيان الصهيوني للفلسطينين الذين يتزوجون من مواطنات إسرائيليات حق المواطنة او العيش داخل الكيان الصهيوني ( الضفة الشرقية ) وقد وصفت منظمة حقوق الإنسان الاسرائيلية هذه القوانين بالعنصرية (32) وهذا لا ينسجم مع التصور الامريكي للديمقراطية . الادوات والإسترابتيات المستخدمة لتحقيق اهداف ايباك : -

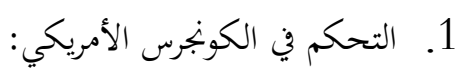

يعدّ الكونجرس اهم الاعمدة الفاعلة لايباك ، ففي الحين الذي ينتظر الشعب الأمريكي من أعضاء الكونجرس حماية الولايات المتحدة ألا أنك بتح الكونجرس ينقاد بشكل اعمى لمصالح اسرائيل ولا يستثنى من ذلك المسيحين ذو الفكر الصهيوني أمثال ديك ارمي أري والذي صرح بشكل علني في ايلول 2002 أن أولويته الأولى في السياسة الخارجية هو حماية إسرائيل(33) ويرجع نجاح أيباك في أروقة الكونجرس إلى مقدرتا على مكافأة أعضاء الهيئة التشريعية ومرشحي الكونجرس الذين يساندون أجندها ، ومعاقبة من يتحدوها وتوجيه تبرعاها للحملة الانتخابية إلى خصومهم السياسيين كما تنظم أيباك بجموعة من الحملات الانتخابية لكل من يدعم سياستها ، وتحث محرري الصحف على الموافقة على المرشحين الموالين لإسرائيل وليس هنالك شك في كفاءة هذه التكتيكات وابرز دليل على ذلك نجاح أيباك في

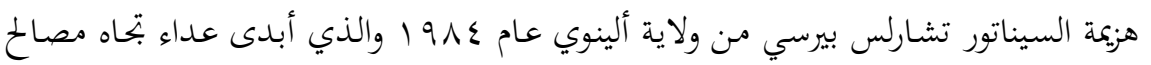
إسرائيل حسبما ذكر أحد أعضاء اللوبي البارزين ، وشرح توماس داين ، رئيس المنظمة يومئذ ما حدث ((إن جميع اليهود في أمريكا، من الساحل إلى الساحل ، اجتمعوا من أجل طرد بيرسي) (مما جعل جميع الساسة الأمريكيين خاضعين للمنظمة بشكل أو بآخر(34) ولكن. تأثير أيباك في الكونجرس يتعدى ذلك وحسبما قال دوجلاس بلومفيلد، أحد الأعضاء السابقين في هيئة العاملي - أيباك ((أن من المألوف أن يرجع أعضاء الكونجرس ومساعدوهم

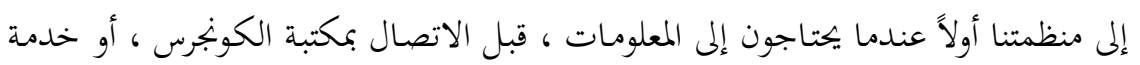


الأبحاث التابعة للكونجرس)) (35) كما تقوم الأيباك بكثير من الاتصالات لصياغة الخطب الخاصة بالمرشحين ، والعمل على إعداد التشريعات التي تتلائم مع المصالح الصهيونية ، وإبداء

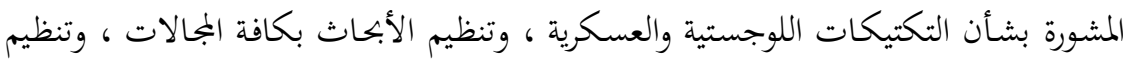

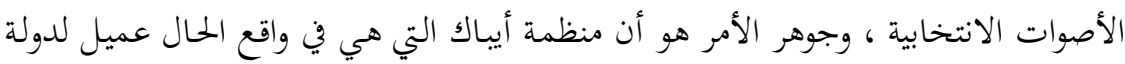

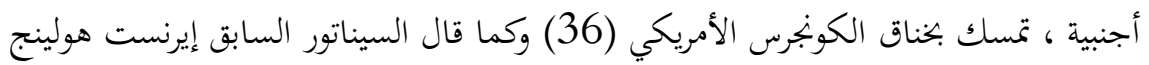
-ديمقراطي من جنوب كارولينا عندما كان على وشك التخلي عن منصبه (( انك لا تستطيع

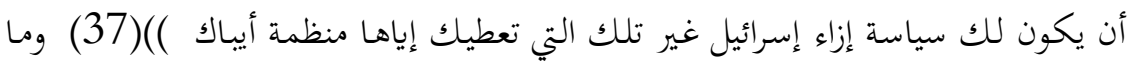

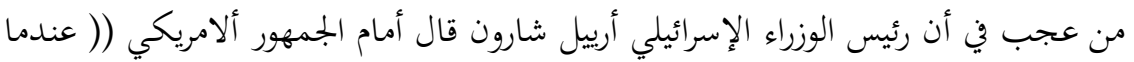

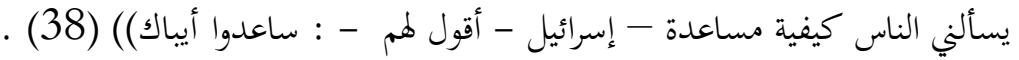

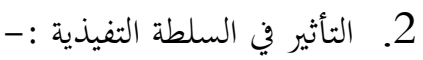

تتأثر السلطة التنفيذية جزئيا من نفوذ الناخب اليهودي ولاسيما في حقبة الانتخابات الرئاسية على الرغم من قلة الأعداد الفعلية لهم لاسيما إذا ما عرفنا إفهم يشكلون إنها

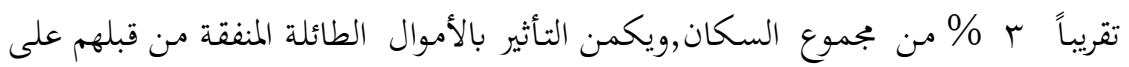

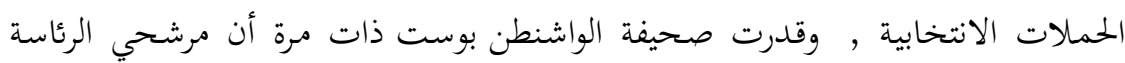

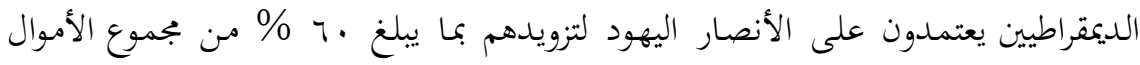

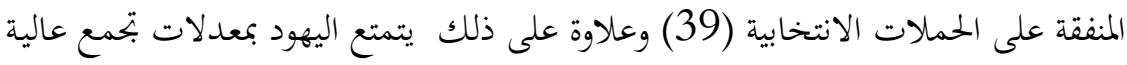

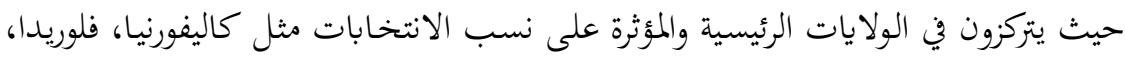

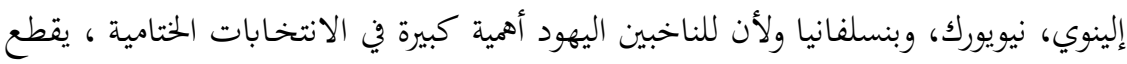
المرشحون للرئاسة شوطا بعيدا في محاولة عدم إثارة عدائهم . 3. قممة معادة السامية : -

ويعد أقوى الأسلاحة التي يستخدمها أي لوبي صهيوني فأي شخص أنس ينتقد

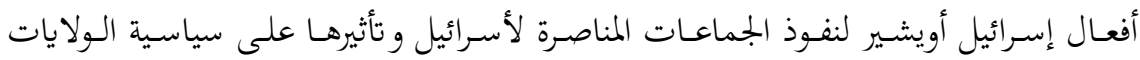

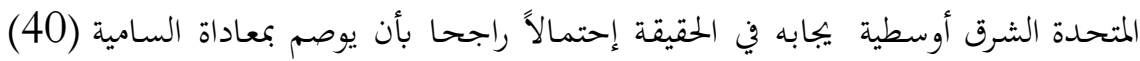
ويشير الإعلام الصهيوني ذاته إلى تلك القدرة وتتغنى الأيباك بهذا النفوذ علناً .

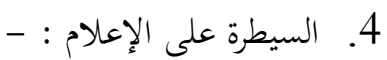


تعد المؤسسـات الإعلامية أحسد أهـم المنشـأت في صـياغة الرأي العـام الامريكي

بشـكل خـاص والعـالمي بشـكل عـام ولا يخفى على الجميـع أن معظم وسـائل الاعـلام في الولايات المتحدة اما ان تكون موالية لإسرائيل او ان تكون صهيونية بالفعل ويؤكد الصحافي إريك ألترمان (( لكل من لا يستطيعون أن يتخيل إنتقاد إسرائيل (41) ويسرد بذلك قائمة تضم أسماء الح كاتب عمود صحافي ، ومعلق يمكن الاعتماد عليهم لمساندة إسرائيل بصورة مطلقة , ولم يجد ألترمان سوى خمسة خبراء ينتقدون بصورة ثابتة سلوك اسرائيل أو يؤيدون المواقف الموالية للعرب )) , وفي حال توارد أخبار سلبية عن الكيان الصهيوني يحبط اللوبي الأخبار عن طريق تنظيم مجموعة من الحمالات وكتابة الرسائل المؤيدة لاسرائيل ، وأقامة التظاهرات ، والبدء بخوض عمليات تحدف إلى مقاطعة وسائل الإعلام التي يعدّ مضموها مناوئا للكيان الصهيوني وذلك عن طريق الحمالات الإعلانية في تلك المؤسسات الإعلامية الأمر الذي يلحق اثأرا اقتصادية ومالية على تلك المؤسسات وقد قال أحد المسئولين في شبكة سي أن أن انه يتلقى في بعض الأحيان 6 آلاف رسالة الكترونية ورسالة نصية قصيرة في يوم واحد تشكو من أن خبرا ما، كان معاديا لإسرائيل (42).

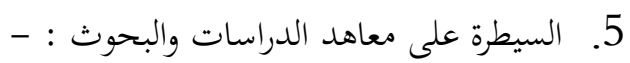

على امتداد ربع القرن الماضي أسست القوى الموالية والمناصرة لإسرائيل حضور

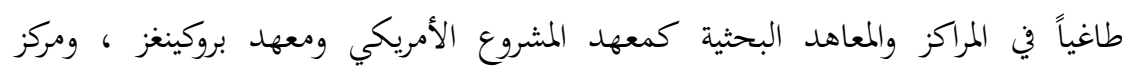

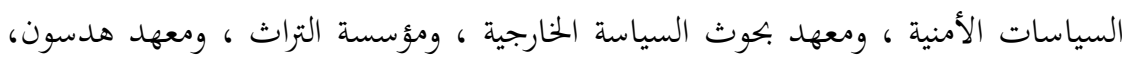
ومعهد تحليل السياسة الخارجية ، والمعهد اليهودي لشؤون الأمن القومي ومراكز الدراسات وصياغة الفكر والرأي العام . 6. محاولة التحكم بالجامعات والمدارس : - -

واجه اللوبي الصهيوني صعوبات جمة في مساعيه وحملاته لخنق الجدل بشأن إسرائيل وشل نشاطات النقاش حولا في أروقة الكليات والمحافل الأكاديمية ، إذ من الصعب تكميم أفواه الأساتذة الكبار الراسخي القدم في مناصبهم الأكاديمية أو تمديدهم أو إسكاتم في حقبة التسعينات عندما كانت عملية التسوية السلمية تشق طريقها وتمضي في سبيلها في أوسلو إذ

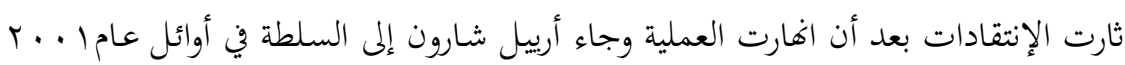


واتسمت بالحدة بوجه خاص عندما أعادت وزارة الحرب الإسرائيلية إحتلال الضفة الغربية من جديد في ربيع ب · . ب وتم استخدم قوة عاتية ضد الانتفاضة الثانية (43)، وتحرك اللوبي بجبروت عدائي لا هوادة فيه ليتدارك تلك الخطوة العسكرية وأثارها وذلك بأنشاء جماعات متعددة لتبيض صفحة الكيان الصهيوني عالميا مثل ( قافلة الديمقراطية) والتي جاءت بمتحدثين اسرائيلين ليحاضروا ويتكلموا في الكليات و والجامعات الأمريكية بشكل مكثف(44)، وفي فاية المطاف ضاعفت ايباك من نفقاها وصرفها على البرامج الرامية إلى إحكام الرقابة على نشاطات الجامعات ولتدريب الشبان الدعاة المروجين للكيان الصهيوني وسياساةا وذلك من أجل إحداث زيادة ضخمة في عدد الطلاب المستغرقين في الهموم والجهه القومي المناصر لإسرائيل (45) . وعلى صـعيد التعلسيم قامست الأيبـاك برعايـة ( المؤسسـة الأمريكيـة - الإسـرائيلية للتعليم) والتي تستهدف أي نشاط تعليمي في الولايات المتحدة إلى جانب إرسال أصاحب القـرار في الـولايات المتحـدة في رحـلات تثقيفيـة لإسـرائيل أو أعضـاء الكـونجرس كـل عـامين (46)، ونظـراً للأهميـة الأكاديميـة في صسياغة الرأي العـام الأمريكي تسعى منظمـات اللـوبي الصهيوني لدفع الكونجرس لتأسيس آليات وسبل منهجية تتجسس من خلالها على الأساتذة وتراقب ما يقولونه عن إسرائيل ولايستثنى من ذلك الحرم الجامعي(47). الباب الثاني : - اجندة ايباك السياسية

لو كان تأثير ايباك مختصرا على المساعدات الاقتصادية الأمريكية للكيان الصهيوني لما كان نفوذه مثيرا للقلق إلى ذلك الحد فالمساعدة الخارجية قيمة ، ولكنها ليست مفيدة بالقدر الذي يجعل القوة العظمى الوحيدة في العالم ، تسخر إمكاناتا الهائلة لخدمة الكيان الصهيوني وتبعا لذلك يسعى اللوبي إلى صياغة العناصر الجوهرية لسياسة الولايات المتحدة الخاصة بالشرق الأوسط وبوجه خاص عمل بنجاح لإقناع الزعماء الأمريكيين بدعم كافة الخروقات المتتابعة من قبل اسرائيل على للفلسطينيين ، وحماية الكيان الصهيوني من خصومه لهن في المنطقة ويمكن اجمال ذلك بالتطرق الى اهم القضايا والمواقف التي أسهمت فيها ايباك بالمنطقة .

$$
\text { 1. ايقاف المشروع النووي الإيراني : - - }
$$


يأتي المشروع النووي الايراني في الوقت الحاضر على رأس الاجندة الحناصة بأيباك إذ تميل إلى وصف أي تميد يصدر ضد الكيان الصهيوني من قبل ايران بأشد العبارات وأقسى الألفاظ وينظر الى ايران على اها أخطر أعداء اسرائيل على الإطلاق واها أرجح الخصوم كفة في إحتمالات حيازة السلاح النووي حاليا واكد على ذلك وزير الحرب الإسرائيلي بنيامين بن أليعازر قبل شهر واحد من غزو العراق ( ) إن العراق مشكلة لكنكم ينبغي أن تفهموا هذه النقطة ، أعني أنكم لو سألتموني اليوم فإيران أخطر من العراق)(48). وتنهال ايباك والمواليين للإسرائيليين بالمقالات التي تحذر من الأخطار الوشيكة التي ستقع إذا ما امتلكت إيران السلاح النووي ، كما تتخذ ايباك خطوات واسعة للتأثير على المجتمع الدولي وتنذره من خطورة أي تغاض أو استرضاء أو مهادنة للنظام الايراني وتلمح بشكل دائم وترسم صورة سوداوية قاتمة إلى أنه ينبغي التحرك للقيام بعمل إستباقي وقائي في حال أخفقت الدبلوماسية وذلك بالتنسيق مع الحكومة الاسرائيلية التي تحذر من امكانية القيام بعمل عسكري إستباقي إن مضت إيران قدما في مشروعها النووي ، وهي تلميحات تقصد في جزء منها الحفاظ على تركيز الولايات المتحدة على هذه القضية .ونجح الضغط الدائم من طرف الأيباك بفرض ضوابط أكثر شدة على الحصار الاقتصادي المفروض على إيران بهدف إعاقة

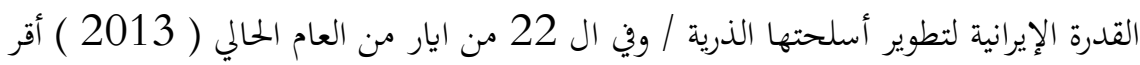
مجلس الشيوخ القرار ذي العدد ( S.Res.65) والذي تضمن ما يأتي : -

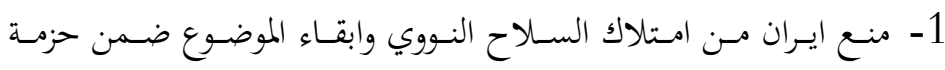

$$
\text { إختصاصات السياسة الأمريكية }
$$

2- تكثيف العقوبات ضد إيران بكافة صورها الاقتصادية والدبلوماسية

3- الوقوف إلى جانب إسرائيل إذا شعرت الدولة اليهوديـة بأهـا بجبرة على

$$
\text { القيام بعمل عسكري للدفاع عن نفسها ضد ايران }
$$

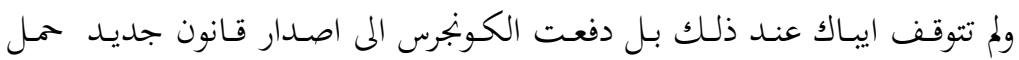

العدد (850 HR) والذي يهدف الى منع حصول ايران على القوة النووية وذلك عن طريق تعزيز إنفـاذ العقوبات الأمريكية الحالية على إيران ، وتوسيع تلك عن طريق فرض عقوبات على أي جهة لها علاقة بحارية كبيرة مع إيران (49) . 
2- تعزيز التعاون الإستراتيجي ما بين إسرائيل والولايات المتحدة : وفقا لما ورد في الموقع الرسمي لأيباك على شبكة الإنترنت فأن الولايات المتحدة وإسرائيل شكلتا شراكة فريدة من نوعها لمواجهة التهديدات الإستراتيجية المتعاظمة في الشرق الأوسط ويمنح هذا الجها التعاوين فوائد جمة لكل من الولايات المتحدة وإسرائيل وهذا الزعم يمثل أحد أركان الإيمان في أوساط مناصري الكيان الصهيوني ودائماً ما يستشهد به ويثار بصورة روتينية من قبل ساسة الكيان الصهيوني والأمريكيين الموالين للكيان الصهيوني وجاءت هجمات الحادي عشر من ايلول/2001 لتعطي اروقة البيت الابيض تبريراً لدعم الولايات

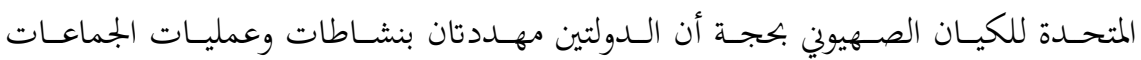

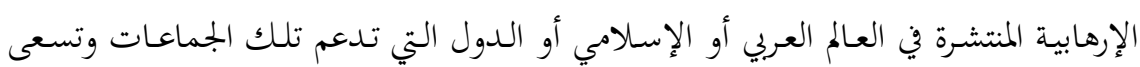

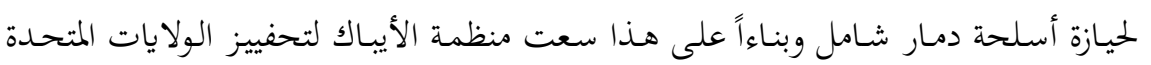

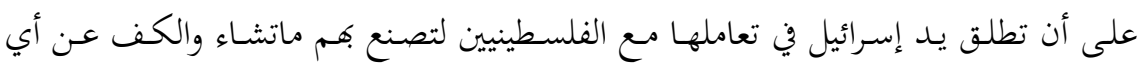
محاولة للضغط على إسرائيل لتقديم أي تنازلات إلى أن يتم سجن جميع الإرهابين الفلسطينين أو قتلهم كما يحمل هذا المنطق في ثناياه فكرة أنه ينبغي على الولايات المتحدة أن تلاحق دولاً بذاتما مثل جمهورية إيران الإسلامية ، وعراق النظام البائد ، وسوريا بشار الأسد ، وان تضيق

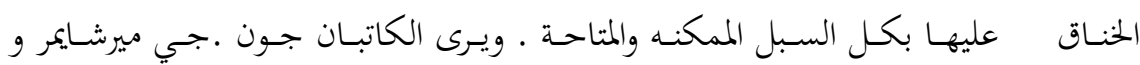
ستيفن.ام.والت في بحوثهما ( بأن إسرائيل في الحقيقة عبء في الحرب على الإرهاب ) إذ يصفان الإرهاب بتكتيك يستخدمه حشد واسع جدا من الجماعات السياسية وهو ليس بالعدو المفرد الموحد المواصفات والمنظمات التي تمدد اسرائيل كحماس أو حزب الله لا تهدد الولايات المتحدة بشكل مباشر إلا إذا ما تدخلت ألاخيرة كما حدث في لبنان عام به 191

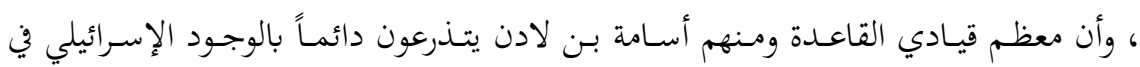
مدينة القدس وعقب هجمات سبتمبر صرح أسامة بن لادن بأن هذه الهجمات ماهي إلا رد فعل للسياسات الأمريكية في الشرق الأوسط ومنها دعم إسرائيل(50) وثار جدل آخر في عام ع . . r عندما تم كشف النقاب عن أن أحد كبار مسؤولي البنتاجون وهو لاري فرانكلين قد قام بتسريب معلومات سرية للغاية إلى دبلوماسي إسرائيلي يساعده إثنان من كبار مسئولي أيباك (51) وعلى الرغم من أن إسرائيل ليست هي الوحيدة التي تتجسس على لى 
الولايات المتحدة ، غير أن إستعدادها التام للتجسس على نصيرها الأكبر يلقي بالمزيد من ظلال الشك على قيمتها الإستراتيجية.

$$
3 \text { - دعم المعونة الأمنية والعسكرية لإسرائيل :- }
$$

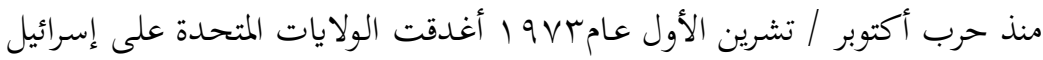
قدرا هائلا من الدعم، وتعد أكبر متلق على الإطلاق لهذا الدعم والمعونات الإجمالية والهبات

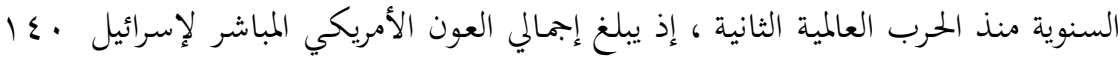

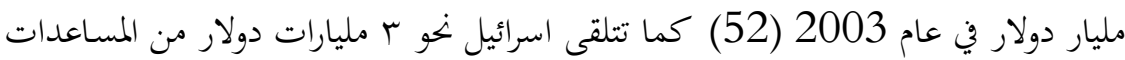

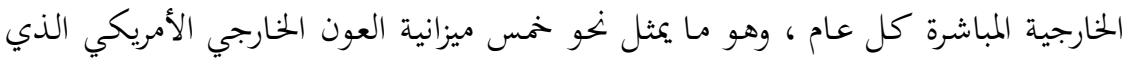
تقدمه الولايات المتحدة .فإذا ما قسنا المسألة بالمقياس الفردي نرى أن الولايات المتحدة تقدم

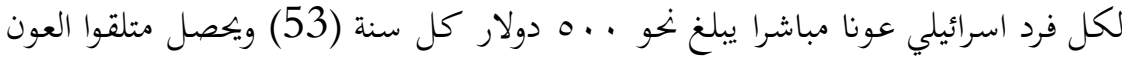
الآخرون على مخصصاقم المالية فصليا أي دفعة كل ثلاثة أشهر، لكن إسرائيل تستلم

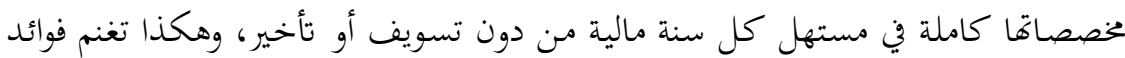
إضافية اكبر، ويطلب من معظم متلقي المساعدات العسكرية الأمريكية أن ينفقوا هذا التمويل

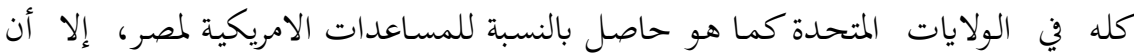
اسرائيل تستطيع أن تستخدم نحو هب \% م من من أموال الدعم المخصصة لها لتدعم صناعاتما

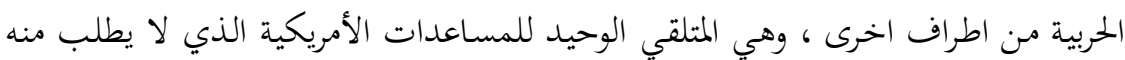

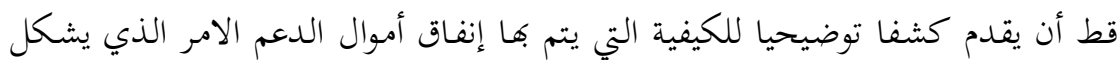

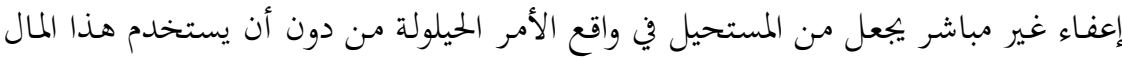

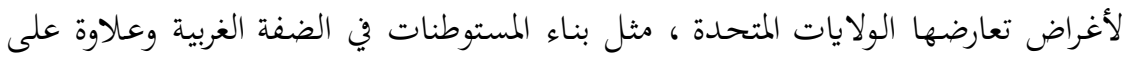

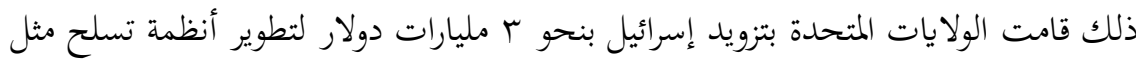

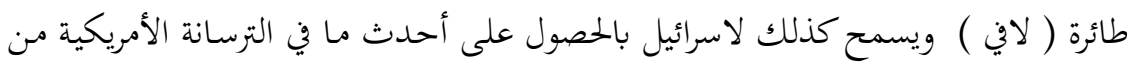
أسلحة متطورة فتاكة مثل مروحيات بلاك هوك وطائرات ف-16 وأخيرا فئإن الولايات

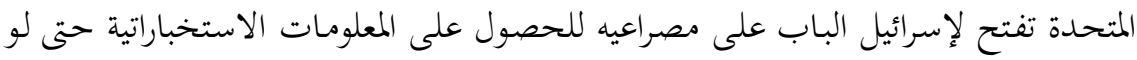
كانت تخص حلفائها في حلف الناتو، هذا فضلاً عن غض الطرف من جانب الولايات

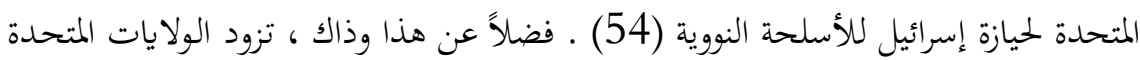


إسرائيل بدعم دبلوماسي مضطرد ومتواصل .فمنذ عام1982 وحتى عام 2006 إعترضت

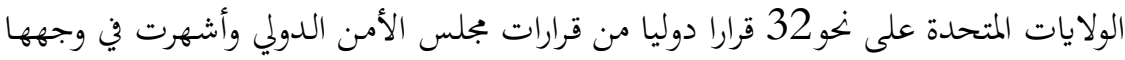

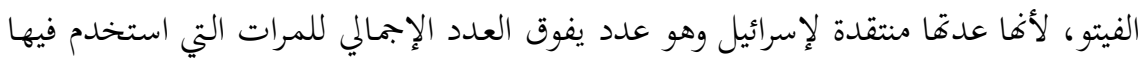

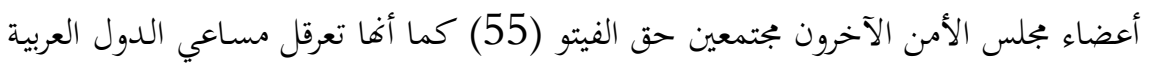

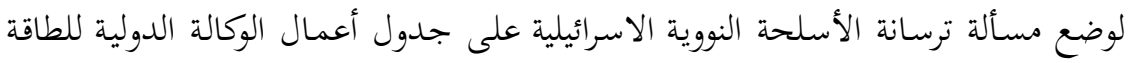

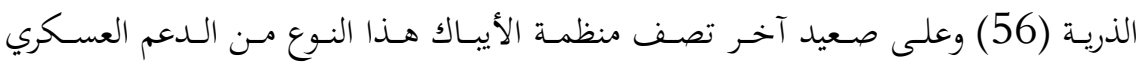

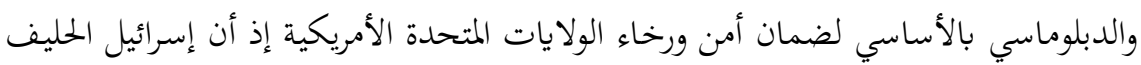

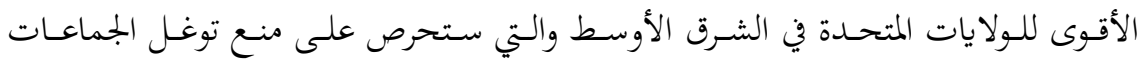

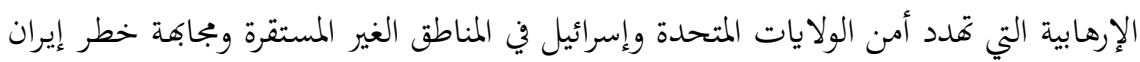

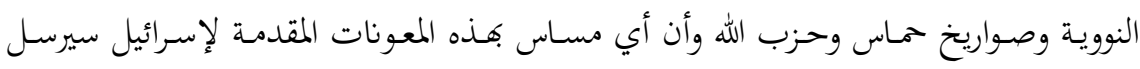

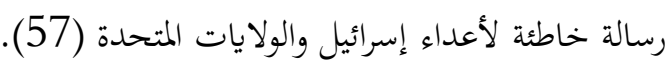
4

تحث منظمة الأيباك الولايات المتحدة الأمريكية والمجتمع الدولي الضغط الدائم على وسلى

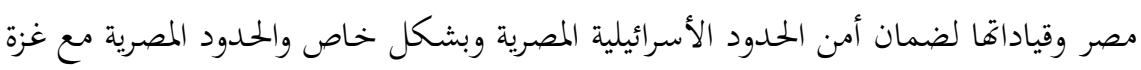
على أن تبقى سيناء خالية من السلاح مع التواجد المستمر للقوات الدولية والمراقبيين الدوليين

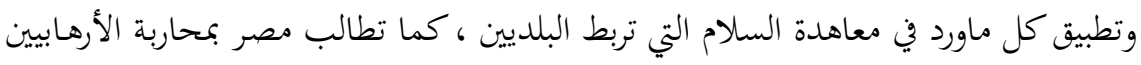

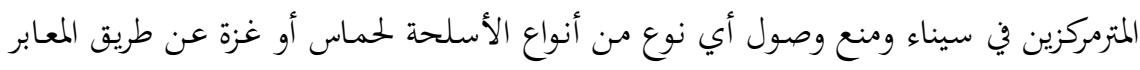

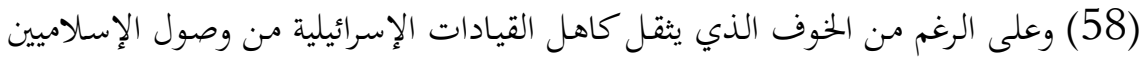

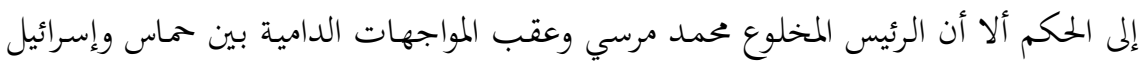

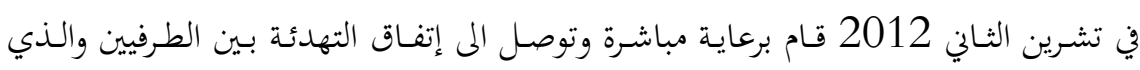

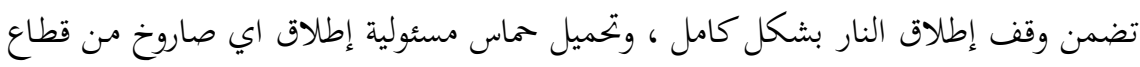

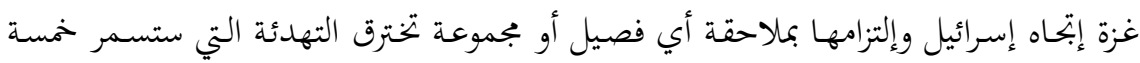

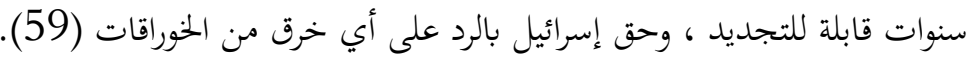

$$
5
$$


تعلن الأيبـاك صـراحة بأن القـد هي العاصـمة الابدية للكيـان الصـهيوني ودفعت

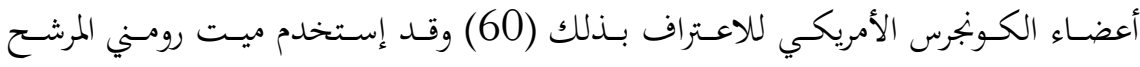
الجمهوري السابق لرئاسة الولايات المتحدة الأمريكية هذه القضية لشن الحرب على منافسه بارك أوبامـا الرئيس الحسالي للولايات المتحـدة الأمريكية إذ أن بـرنامج الحـزب الديقراطي لعام 2012 والذي تم توزيعه قبيـل إفتتاح مؤتمر الحـزب الـيمقراطي الذي عقــ بمدينـة تشـارلوت التابعة لولاية كارولينا الشمالية لإختيار باراك أوباما مرشحاً للحزب في السباق الرئاسي لم يرد به أي ذكر للقدس أو حتى إسرائيل ، وعدّ رومني أن عدم الإعتراف بالقدس كعاصمة للكيان الصهيوني بالأمر المخزي وإبعاد الولايات المتحدة الأمريكية عن حليفتها الأبدية( اسرائيل ) لكن سرعان ما قام أوباما بتعديل البرنامج ليتوافق مع برنابجه في 2008 والذي صرح فيه أن القدس هي العاصمة الأبدية لإسرائيل (61) وقد حصل على الثناء بعد ذلك من ايباك .

$$
6
$$

لم تبدأ ايباك بالضغط على إدارة بوش لدفعها لإستهداف سوريا قبل أذار من عام r . . r ، وذلك لأفم كانوا مستغرقين إلى الحد الأقصى في جهود التحريض لشن الحرب على العراق وما ان اكتملت عملية احتلال العراق في منتصف نيسان حتى بدأت ايباك بمساعيها لحث واشنطن على إستهداف سوريا (62) وبدعم موازي من قبل القادة الصهاينة وعلى سبيل المثال أجرى شارون ووزير حربه شاؤول موفاز مقابلات قصد منها تسليط وهـج إعلامي في 17 نيسان وذلك بأستخدام الصحف الاسرائيلية إذ ذكرت جريدة يديعوت أحرنوت ان شارون طالب الولايات المتحدة بأن تمارس ضغطاً شديداً على سوريا (63) وصرح موفاز لمعاريف قائلاً ( لدينا لائحة طويلة من المسائل التي نفكر بأن نطالب السوريين بها ، ومن المناسب أن نقوم بهذا من خلال الأمريكيين ) (64) وتحدث كذلك مستشار شارون لشؤون الأمن القومي إيفرايم هالفي إلى جمهور أحتشد في قاعة المحاضرات في معهد واشنطن لسياسات الشرق الأدنى ، وأخبرهم بأن من المهم الآن بالنسبة للولايات المتحدة أن إن إن تتعامل بحزم وخشونة مع سوريا ، وأوردت صحيفة واشنطن بوست أن إسرائيل تغذي الحملة ضد سوريا بإمداد أجهزة الاستخبارات الأمريكية بتقارير عما يقوم به الرئيس السوري بشار 
الأسد من أعمال كمساندة حزب الله اللبناني (65) وكلنا نشاهد ونرى نتيجة هذه الضغوط

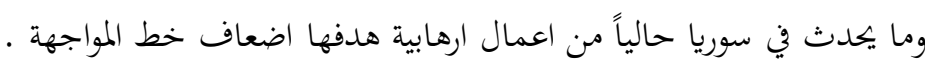
وكان بعض من أبرز أعضاء اللوبي قد قدموا الحجج ذاتما وجادلوا بالطريقة نفسها

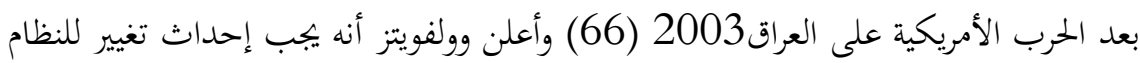

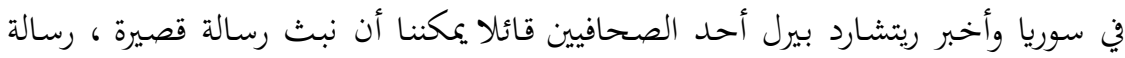

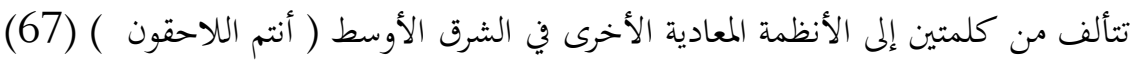

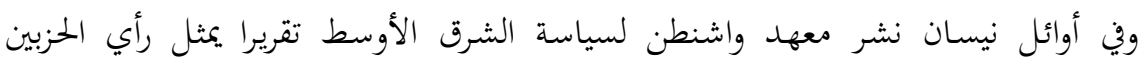

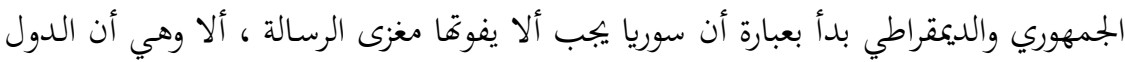

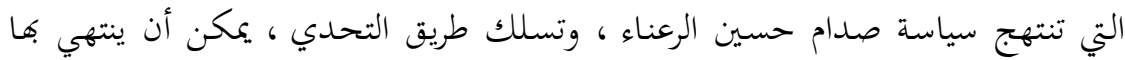
المطاف إلى مواجهة ما واجهه من مصير(68) ونجحت سياسة ايباك بالضغط على عضو الكونجرس ونائب نيويورك إيليوت اينجيل وتم اصدار قانون محاسبة سوريا وإسترداد السيادة

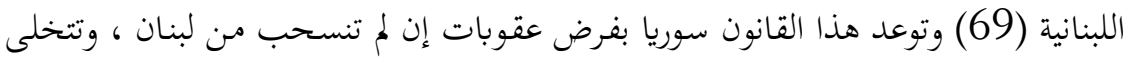
عن أسلحة الدمار الشامل وتوقف دعمها للإرهاب ( حزب الله ) ، كما طالب سوريا ولبنان بإتخاذ خطوات عملية ملموسة لإبرام سلام مع إسرائيل وأفاض اللوبي الصهيوني وعلى راسهم لهاب

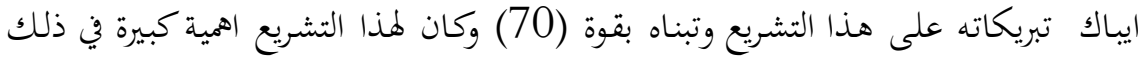
الوقت لاسيما ان إدارة بوش لم تكن شديدة الحماس لطرح القانون سابق الذكر وتبنيه بقوة

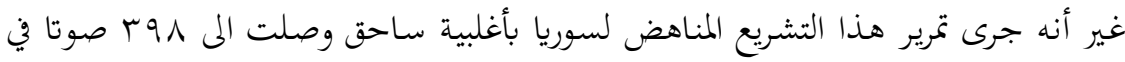
بجلس النواب وبنسبة 9 م إلى ع في مجلس الشيوخ ، وقام بوش الابن بالمصادقة على القانون

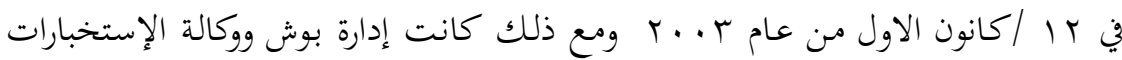

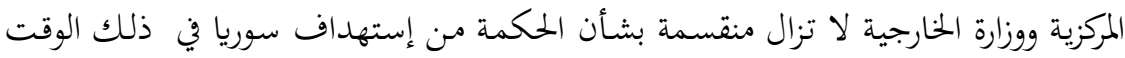

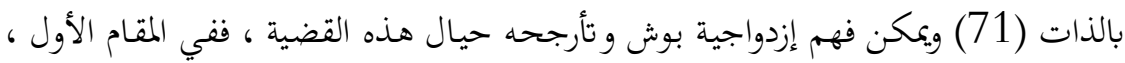
دأبت الحكومة السورية على إمداد الولايات المتحدة بمعلومات إستخباراتية مهمة عن تنظيم القاعدة منذ هجمات الحادي عشر من ايلول 2001 كما أها حذرت الولايات المتحدة

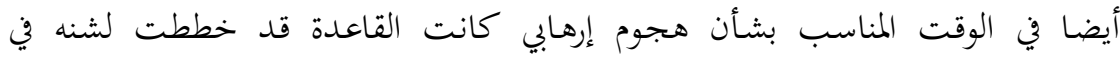
الخليج(72) وعلاوة على ذلك أمنت سوريا لمققي الإستجواب في الـ (CIA ) سبل فئل 
الوصول إلى محمد الزمار، الذي راجت مزاعم بأنه هو من قام بتجنيد العناصر التي شنت هجمات 11 سبتمبر وإختطفت الطائرات ، فإستهداف نظام بشار الأسد من شأنه أن يهدد حلقات الإرتباط الثمينة هذه ويقوض جهود الحرب الكبرى على الإرهاب كما لم تكن سوريا تمثل تمديدا للولايات المتحدة بحال من الأحوال ، ومع ذلك أصر الكونجرس على تصعيد الضغوط على سوريا ، وكان الدافع الأكبر وراء ذلك هو الإستجابة لضغط مارسته ايباك

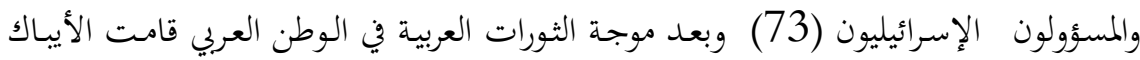

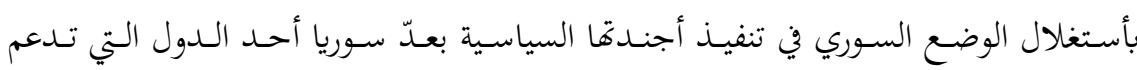

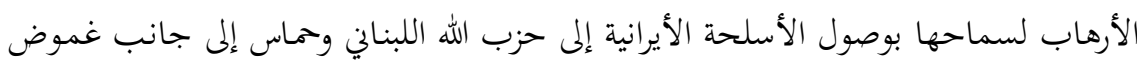
مشروعها النووي المحظور حسب وصفهم وطالبت الأيباك في موقعها الإلكتروني ( أنه حسان الوقت لبشار الأسد أن يتنازل عن السلطة ) (74) . - 7

تصف منظمة الأيباك حزب الله بالمنظمة ( الأرهابية ) التابعة لأيران والتي تشكل خطراً مباشراً على مصالح الولايات المتحدة وإسرائيل إذ أن حزب الله ثاني أكبر مسئول بعد القاعدة عن قتل الأمريكيين في هجمات إرهابية في مختلف بلدان العالم حسب وصفهم إلى جانب قيامـه بعدة هجمات على إسرائيل منذ إنسـحابه مـ شثمال لبنـان في عـام 2000 ، ويعد أسطول الصواريخ التـابع لحزب الله والموجه على مناطق إسرائيلية أكبر مخاوف إسرائيل (75) وسعت الأيباك الى أن يتم تصنيف حزب الله من قبل الإتحاد الأوروبي كأحد المنظمات الأرهابية والتي لا تمت للسياسة أو المقاومة بأي شكل ، وبرعاية جلية من منظمة الأيباك قام بجلـس الشـيوخ والكـونجرس بإرسـال رسـالتين ، الأولى موقعـة مـن قبـل 269 مـن أعضـاء الكونجرس إلى 22 وزارة في الإتحاد الأوروبي تربط بين حزب الله ودوره في مساندة نظام بشار الأسـد وتم إرسـال هـذه الرسـالة بتـاريخ 27 ايلول/ 2012 والأخـرى موقعـة أيضـا مـن قبـل 255 من أعضاء الكونجرس موجهة إلى وزير خارجية قبرص والذي كان يترأس دورة المجلس الأوروبي مشسيرين أن قبرص هيـا أيضـاً أحسل ضـحايا حزب الله ولـديها الآن الفرصـة التاريخيـة لتوصيف حزب الله بالطريقة التي يراها الكونجرس الأمريكي ( منظمة ارهابية ) وتم إرسال هذه

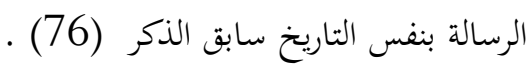



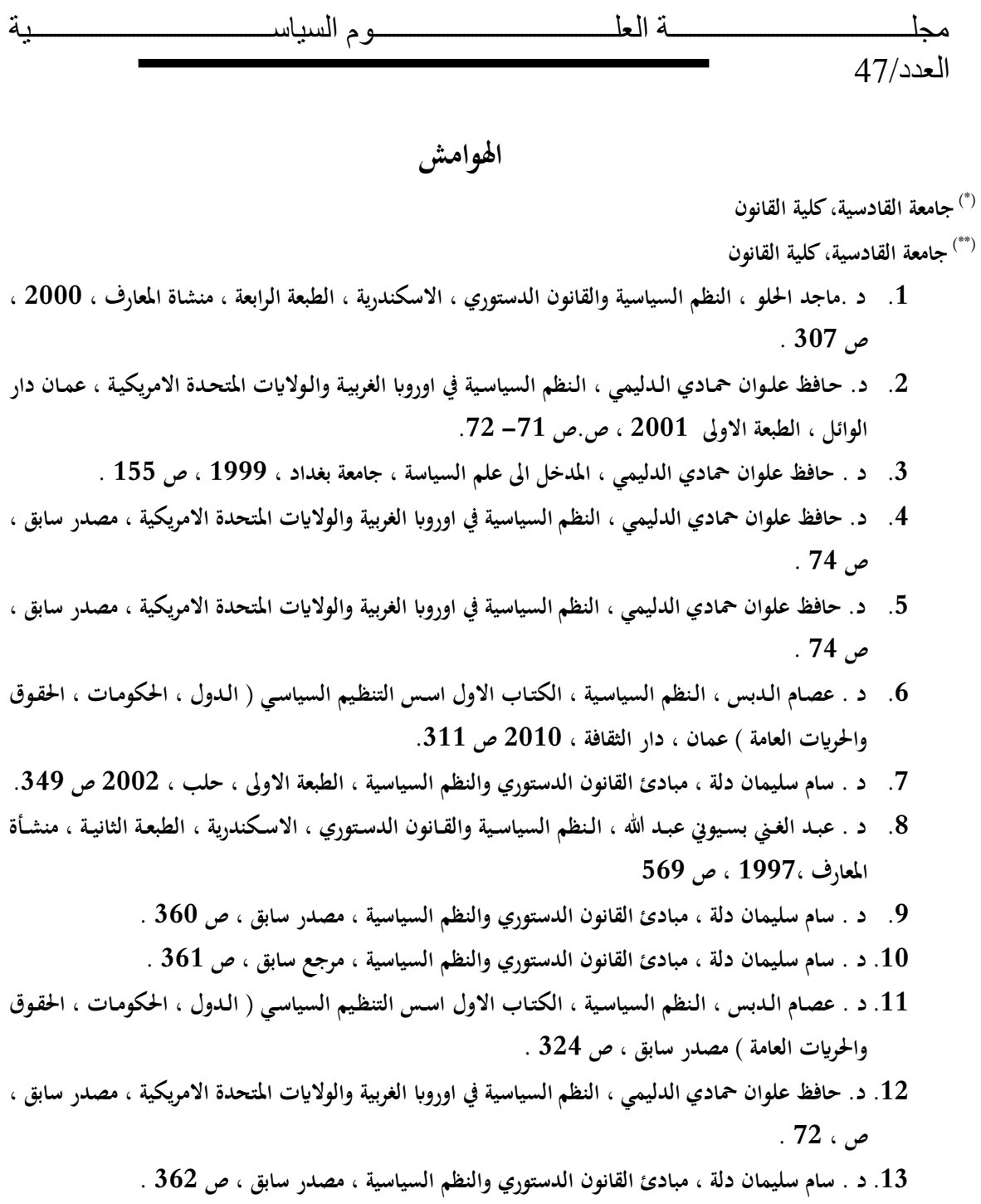

14. Bard, Mitchell Geoffrey; Schwartz, Moshe (2005). 1001 Facts Everyone Should Know About Israel. Lanham, Maryland: Rowman \& Littlefield. p. 148. Retrieved March 22, 2012

15. Michael Oren (2007). Power, Faith, and Fantasy: America in the Middle East 1776 to the Present (New York: W.W. Norton \& Company) p. 536.

16. Lenczowski, George (1990). American Presidents and the Middle East. Duke University Press. p. 157.

17. Jeffrey H. Birnbaum, "Washington's Power 25," Fortune, December 8,1997 . AIPAC was ranked number 4 in a similar study conducted 
in 2001. See Jeffrey $H$. Birnbaum and Russell Newell, "Fat and Happy in D.C.," Fortune, May 28, 2001.

18. Richard E. Cohen and Peter Bell, "Congressional Insiders Poll," National Journal. March 5, 2005.

19. Steven M. Cohen, The 2004 National Survey of American Jews, sponsored by the Jewish Agency for Israel's Department of Jewish Zionist Education, February 24, 2005. The figure two years earlier was 28 percent. See Steven M. Cohen, The 2002 National Survey of American Jews, sponsored by the Jewish Agency for Israel's Department of Jewish Zionist Education, conducted in NovemberDecember 2002.

20. Esther Kaplan, "The Jewish Divide on Israel," Nation, July 12, 2004; Eric Yoffie, "Reform the Conference," Forward, August 2, 2002.

21. Darrell L. Bock, "Some Christians See a 'Road Map' to End Times," Los Angeles Times, June 18, 2003.

22. AIPAC: Official website/about http://www.aipac.org .

23. AIPAC: Claims and Facts 101 the Times OF Israel. 12/2/2012.

24. AIPAC: Official website/our mission http://www.aipac.org .

25.Jhon.J.Mearsheimer \& Stephen.M. Walt "The Israel Lobby and the US foreign policy”, Harverd university, March 2006.

26. AIPAC: Official website/how we work? http://www aipac.org .

27.Justin McCarthy, The Population of Palestine: Population History and Statistics of the Late Ottoman Period and the Mandate (NY: Columbia University Press, 1990), p.11.

28. Simha Flapan, TheBirth of Israel: myths and realities (NY: Pantheon books 1987) p. 44.

29. Trevor N. Dupuy, Elusive Victory: The Arab-Israeli Wars, 19471974 (New York: Harper and Row, 1978), pp. 3-19, 121-125, 146147, 212-214, 231-244, 333-340, 388-390, 597-605, 623-633; pp. 189-199.

30. Uri Bar-Joseph, "The Paradox of Israeli Power," Survival, Vol. 46, No. 4 (Winter 2004-05), pp. 137-156.

31. Amiram Barkat, "Majority of Israelis Are Opposed to Intermarriage, Survey Finds," Ha'aretz, September 15, 2003. 
32. "The Official Summation of the Or Commission Report," published in Ha'aretz, September 2, 2003.

33.James Bennet, "Israel Blocks Palestinians from Marrying into Residency,” New York Times, July 31, 2003.

34.Jake Tapper, "Questions for Dick Armey: Retiring, Not Shy," New York Times Magazine, September 1, 2002.

35. Edward Tivnan, The Lobby: Jewish Political Power and American Foreign Policy (NY: Simon and Schuster, 1987), p. 191.

36. Camille Mansour, Beyond Alliance: Israel in U.S. Foreign Policy, trans. James A. Cohen (NY: Columbia University Press, 1994), p. 242.

37. Idem, "Leaders Stress American Side of AIPAC," Forward, May 27, 2005.

38. Sen. Hollings Floor Statement Setting the Record Straight on His Mideast Newspaper Column," May 20, 2004, a copy of which can be found on the former Senator's web site.

39. Published in an AIPAC advertisement in the Chicago Jewish Star, August 29-September 11, 2003.

40. James D. Besser, "Jews' Primary Role Expanding," Jewish Week, January 23, 2004.

41. Phyllis Chesler, The New Anti-Semitism: The Current Crisis and What We Must Do about It (San Francisco: Jossey-Bass, 2003).

42. Eric Alterman, "Intractable Foes, Warring Narratives," MSNBC.com, March 28, 2002.

43. Felicity Barringer, "Some U.S. Backers of Israel Boycott Dailies Over Mideast Coverage That They Deplore," New York Times, May 23, 2002.

44. James D. Besser, "Turning up Heat in Campus Wars," Jewish Week, July 25, 2003

45. Besser, "Turning up Heat." In 2002 and 2003, AIPAC brought 240 college students to Washington, DC for intensive advocacy training, sending them back to school to win over campus leaders to Israel's cause. Pomerance, "Israel Forces Winning." In the spring of 2005 , it hosted 100 student government presidents $(80$ of whom 
were not Jewish) at its annual conference. Nathaniel Popper, "ProIsrael Groups: Campuses Improving,” Forward, June 24, 2005.

46. Charles and Lynn Schusterman Family Foundation."American Israel Education Foundation". Retrieved November 27, 2011.

47. Stanley Kurtz, "Reforming the Campus: Congress Targets Title VI," National Review Online, October 14, 2003.

48. Quoted in Alan Sipress, "Israel Emphasizes Iranian Threat," Washington Post, February 7, 2002. This article, which was written as Sharon was arriving in Washington, makes clear that Tel Aviv was "redoubling its efforts to warn the Bush administration that Iran poses a greater threat than the Iraqi regime of Saddam Hussein."

49. AIPAC: Official website/policy agenda-prevent Iran Nuclear Program http://www.aipac.org .

50. Downloaded from AIPAC's website http://aipac.org/documents/unitedefforts.html] on January 12, 2006.

51. Former reference "The Israel Lobby and the US foreign policy", P.5

52. Jeffrey Goldberg, "Real Insiders: A Pro-Israel Lobby and an F.B.I. Sting," New Yorker, Vol. 81, issue 19 (July 4, 2005), pp. 34-40.

53. According to the U.S. Agency for International Development's (USAID) "Greenbook," which reports "overseas loans and grants," Israel has received $\$ 140,142,800$ (in constant 2003 dollars) from the United States through 2003. Downloaded from the "Greenbook" web site [http://qesdb.cdie.org/gbk/] on November $8,2005$.

54. According to the "Greenbook," Israel received about $\$ 3.7$ billion in direct aid from the United States in 2003. Israel's population according to the International Institute for Strategic Studies [IISS] and the CIA is 6,276,883. IISS, The Military Balance: 2005-2006 (Oxfordshire: $\quad$ Routledge, 2005), p. 192; [http://www.cia.gov/cia/publications/factbook/]. That averages out to $\$ 589$ per Israeli. If one assumes the same population size and $\$ 3$ billion in total aid, then each Israeli receives $\$ 478$.

55. Seymour M. Hersh, The Samson Option: Israel's Nuclear Arsenal and American Foreign Policy (New York: Random House, 1991). 
56. Donald Neff, "An Updated List of Vetoes Cast by the United States to Shield Israel from Criticism by the U.N. Security Council," Washington Report on Middle East Affairs, May/June 2005.

57. Marc Perelman, "International Agency Eyes Israeli Nukes," Forward, September 5, 2003.

58. AIPAC: Official website/policy agenda-support security assistance http://www.aipac.org

59. AIPAC: Official website/issues-Egypt and Sinia http://www.aipac.org

60. Alwatan Voice "Text of Israel-Hamas cease-fire agreement" on November 2012, download from [http://www.alwatanvoice.com/arabic/news/2012/11/21/336749.html

61. AIPAC: Official website/issues-Jerusalem http://www.aipac.org

62. Konrad Yakabuski, "Obama democrats recognize Jerusalem as the capital of Israel", (Charlotte, N.C. - The Globe and Mail), September 5, 2012.

63. Daniel Sobelman and Nathan Guttman, "PM Urges U.S. to Keep Heat on Syria, Calls Assad 'Dangerous', Ha'aretz, April 15, 2003.

64. Molly Moore, "Sharon Asks U.S. to Pressure Syria on Militants," Washington Post, April 17, 2003.

65. Karen DeYoung, "U.S. Toughens Warnings to Syria on Iraq, Other Issues," Washington Post, April 15, 2003.

66. Ori Nir, "Jerusalem Urges Bush: Next Target Hezbollah," Forward, April 11, 2003.

67. David R. Sands, "Hawks Recycle Arguments for Iraq War against Syria," Washington Times, April 16, 2003.

68. Nathan Guttman, "Some Senior U.S. Figures Say Syria Has Crossed the Red Line," Ha'aretz, April 14, 2004.

69. Robin Wright, "U.S. Insists Syria Alter Its Course," Los Angeles Times, April 14, 2003.

70. DeYoung, "U.S. Toughens Stance." There was a story in Ha'aretz ("NY Congressman Says Will Push Bill to Pressure Syria") on August 19, 2003.

71. Ron Kampeas, "Bush, Once Reluctant on Sanctions, Prepares to Take a Tough Line with Syria," JTA, March 16, 2004. 


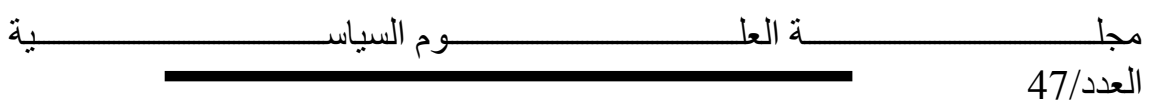

72. Julian Borger, "Bush Vetoes Syria War Plan," Guardian, April 15, 2003.

73. Seymour M. Hersh, "The Syrian Bet," New Yorker, Vol. 79, issue 20 (July 28, 2003), pp. 32-36.

74. Marc Perelman, "Syria Makes Overture over Negotiations," Forward, July 11, 2003.

75. AIPAC: Official website/issues-syria http://www.aipac.org

76. AIPAC: Official website/issues-hezboallah http://www.aipac.org 